\title{
Strategies to Manage Risk and their Role in Impacting Economic Performance among Farm Households
}

\author{
Hisham S. El-Osta ${ }^{1}$ \\ Correspondence: Economic Research Service, United States Department of Agriculture, Washington DC, USA
}

Received: December 6, 2017

Accepted: January 11, $2018 \quad$ Available online: January 17, 2018

doi:10.11114/aef.v5i2.2937

URL: https://doi.org/10.11114/aef.v5i2.2937

\begin{abstract}
Data from the 2015 ARMS and a multinomial probit regression model were used in an attempt to discern the impact of socio-economic factors on the likelihood of a farm household falling in a favorable income-wealth category delineated by above-median income and wealth levels. A primary determinant considered was the number of risk management strategies utilized by the farm household. Findings indicate that farmers who layer up the adoption of risk management strategies are most likely to secure an economic performance status characterized by 'low-income, high-wealth'. Aging farm operators and those with college education and who operate larger sized farms are found more likely to be in the top economic performance category of 'high-income, high-wealth'.
\end{abstract}

Keywords: economic performance, risk-management strategy, zero-inflated poisson model, multinomial probit regression

JEL Classification: G22, D14, Q12, Q18, R11

\section{Introduction}

The structure of farming in the U.S. since the early 1970s continues to change to where a larger share of farm production, in addition to the use of advanced technology and the ownership of farmland, is controlled by a few, yet increasing number of larger farming operations (Heady and Sonka 1974; Gebremedhin and Christy 1996; Ollinger, MacDonald, and Madison 2005). White and Hoppe (2012) showed that between 1991 and 2009, agricultural production shifted to larger farms. In 1991, for example, family farms with production of more than $\$ 1$ million accounted for 21 percent of total production. By 2009, this sales class accounted for 39 percent of farm production. Over the same time period, the same study used the median rate of return on equity to document the higher profitability of these larger farms compared to farms in smaller sales categories. O'Donoghue et al. (2011) pointed to innovations in farm organization, business arrangements, and production practices as factors that have allowed farmers to produce more farm output at lower cost. Further, the study showed that a likely contributing factor to the nearly 50 percent increase in U.S. agricultural productivity since 1982, which has long been considered as the main contributor to economic growth in U.S. agriculture (see, Ball, Butault, and Nehring 2002), was the augmented use of risk management tools (e.g., use of contracts and crop insurance, etc.).

While risk consideration has been extensively examined in production agriculture (e.g., Mapp et al. 1979; Just and Pope 1979; Antle 1983; Harwood et al. 1999; Meuwissen, van Asseldonk, and Huirne 2008; Ullah et al. 2016), exploring the relationship between risk management per se and economic performance is apt to contribute yet another perspective to the continually growing body of risk-related literature. To mitigate the risk associated with farm production, many farmers rely primarily on their participation in off-farm work and/or in farm programs. For example, Fuller and Mage (1976) noted that off-farm employment enables farm families to spread income risk. Studies by Key, Prager, and Burns (2017) and Hungerford, Motamed, and Cessna (2017) point to newly created programs in the 2014 Farm Act that are tied to fluctuations in prices, yields, and revenues, and which are aimed at risk reduction by producers.

Yet for many others, lowering the probability of adverse economic outcomes is managed by choosing among many alternatives of risk management strategies. The specific objective of this paper is to discern the impact of a farmer adopting a risk management tool, either singly or in combination with other risk management strategies, on the

\footnotetext{
${ }^{1}$ Hisham El-Osta is an agricultural economist with the Economic Research Service, United States Department of Agriculture. The views expressed are those of the author and should not be attributed to ERS or USDA..
} 
likelihood of achieving a favorable economic position. The paper develops a count index of risk-management strategy utilization in order to test primarily the significance of its role, along with the roles of other socio-economic determinants based on data from the 2015 Agricultural Resource Management survey (ARMS), in securing the placement of the farm operator household in an advantageous economic category. ${ }^{2}$

The question of how best to assess the relative economic performance of a farm business has been addressed in a number of studies (see Mishra, El-Osta, and Johnson 1999; Mishra and Morehart 2001). A commonly used indicator of a favorable financial performance by a farming operation categorizes the farm based on whether its net farm income is positive and its debt-to-asset ratio is less than forty percent (see Park et al. 2011). Hoppe et al. (2005) characterized top-performing farms as those farm businesses in the highest quartile of the distribution of farm operator's labor and management income (OLMI). ${ }^{3}$

A potential weakness of these indicators of financial well-being is that both primarily utilize income from farming, which is highly variable due to the vagaries in weather and/or shifts in market conditions and in prices of farm output (see Mishra and Sandretto 2002; and Dismukes and Durst 2006). Additionally, to the extent that the relative solvency-based financial indicator depends also on the debt-to-asset ratio which has a long right tail, this measure of economic well-being hence cannot be calculated for the relatively few farming operations that own no assets (Ahrendsen and Katchova 2012). ${ }^{4}$

Mishra et al. (2002) sought an indicator of favorable economic performance for farm households by looking first at both the income and wealth levels of the farming unit in comparison to a median-income and median-wealth of all U.S. households. The result of this relative measure of well-being was the placement of the farm household in one of four quadrants: lower-income and higher-wealth, higher-income and lower-wealth, lower-income and lower-wealth, and higher-income and higher-wealth.

The closing of the income gap between farm and non-farm households since 1998, which has been attributed to the growth in the earnings from off-farm sources resulting primarily from greater returns to farm household skills employed off the farm (Brown and Weber 2013), has made the use of the 'high-income, high-wealth' quadrant as developed by Mishra et al. (2002), and as was implemented by El-Osta, Mishra, and Morehart (2007), as a means of categorizing advantageous economic performance less relevant. For example, in 2002, almost half of U.S. farm households had both higher incomes and greater wealth than all U.S. households (Mishra et al. 2002); a proportion that now, based on the 2015 ARMS, stands at 64 percent. In this paper, for example, top-performing farm households are defined as those households with farm household income and farm household wealth in excess to a median-income and median-wealth of all farm households; and not of all U.S. households as was done in the study by Mishra et al. (2002). As shown in the scatter plot in Figure 1 which depicts how farm households are distributed among the four quadrants delineated relative to a median-income and a median-wealth of farm households ( $\$ 76,700$ and $\$ 833,200$, respectively), about 34 percent of all farm households in 2015 are found in this category of top-economic performance. ${ }^{5}$ By the same token, about 16 percent of farm households are found located in the less desirable but nevertheless economically favorable categories of 'high-income, low wealth' and of 'low-income, high-wealth'.

\footnotetext{
${ }^{2}$ The main null hypothesis to be tested in this paper is that there is no significant statistical relationship between the count index of risk management strategies employed by the farm operator and the likelihood of a favorable economic outcome for the farm household.

${ }^{3}$ As reported by Hoppe et al. (2005) OLMI adjusts net farm income for implicit costs of capital and unpaid labor contributed by family members other than the operator which is assessed based on mean wage earned by hired farm labor in a State, as reported by the USDA's National Agricultural Statistics Service.

${ }^{4}$ Data from the 2015 ARMS show 1,126 farms out of the 2.03 million farms represented in the sample with no total farm assets.

${ }^{5}$ While the percentages shown in Figure 1 reflect the distribution of all farm households in the 48 contiguous states in 2015 among the four quadrants, the figure itself excludes those income and wealth levels that exceed the range depicted in the axes of the figure. This was done to allow for a clearer depiction of where the bulk of the households are located with regard to the corresponding farm households' median-income and median-wealth reference lines depicted in the figure.
} 


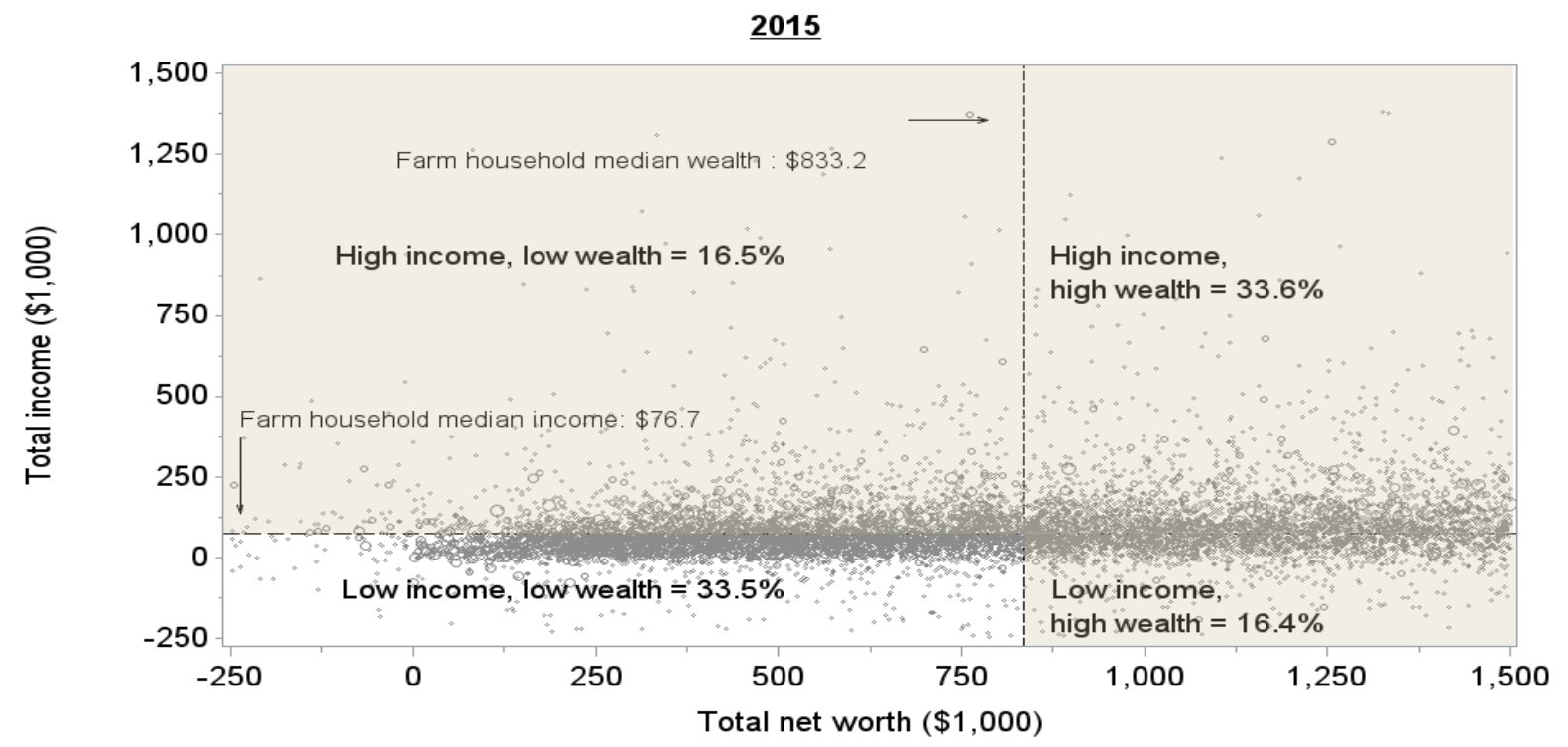

Data source: 2015 ARMS

Size of the bubble $=$ survey expansion factor

Source: estimated by the author using 2015 ARMS

Figure 1. Economic well-being of farm households: comparison is relative to a median farm household

\section{Previous Research}

Barry, Escalante, and Bard (2000) noted that agricultural economists have for long examined risk, both conceptually and empirically, with the main focus being oriented towards risk measurement, identification of risk attitudes, and the assessment of the effectiveness of various risk management practices (e.g., Barry 1984; Robison and Barry 1987; Harwoood et al. 1999; Hardaker, Huirne, and Anderson 1997; among others). The early and important work by Gale Johnson (1947) and by Earl Heady (1952) on financial, marketing, and farm business risk, in addition to risk aversion was emphasized by Barry and Stanton (2003).

Various estimation techniques were implemented by researchers as part of investigating risk exposure in farming. Early research on the subject utilized mathematical programming with a focus on examining whole farm planning in the presence of risky alternatives, and under conditions of uncertainty (e.g. Fruend, 1956; Hazell 1971; Mapp et al. 1979). In an effort to examine systematic (i.e., risk correlated among producers) and non-diversifiable risk, later studies, for example, implemented the use of the coefficient of variation of total indemnities paid by crop insurers in addition to a selection of parametric and non-parametric methods to estimate probability functions of crop yields, which in turn, tend to have implications on the income generating capacity and profits of farm businesses (e.g., Miranda, and Glauber. 1997; Atwood, Shaik, and Watts 2003; Tack, Harri, and Coble 2012). Conditional quantile regression is applied along with the certainty equivalent concept and welfare measures by Chavas and Shi (2015) to analyze the effects of genetically modified (GM) seed technology and management on risk in corn production in Wisconsin. Hungerford and O'Donoghue (2016) used logistic and Tobit regression procedures in addition to simulation technique to provide detailed examination of the potential for reducing revenue risk among cotton producers by two specific programs [e.g., the Supplemental Coverage Option (SCO) and the Stacked Income Protection Plan (STAX)]. The study's findings showed that under the assumption that a cotton farmer selects Revenue Protection with 70 percent coverage, which is considered by the authors as the most common policy and coverage rate among cotton producers, STAX tends to provide higher net payments to producers and greater risk reduction than SCO.

Hoppe et al. (2005) used data from the 2001 ARMS and cross-tabulation to examine the characteristics of top-performing farm households. Basing top-performance on whether the farm household is in the top quartile of the distribution of farm operator's labor and management income, findings showed that operator characteristics, business organization, and farm contracting did not seem to be strongly related to financial performance. The study found that farms of top-performing farm households were very large, were more likely to be partnerships or family corporations, and that their operators were younger, and had more formal education than bottom performers. Research by D'Antoni, Mishra, and Chintawar (2009) used 2004-2006 ARMS data along with the multinomial logit regression procedure to predict the likelihood of financial stress among young and beginning farmers based on a solvency measure developed by the Economic Research Service. Findings from the study pointed to farmer's age, size of operation, farm ownership, 
and farm type as important factors in the determination of the financial position of the farm business. Kuethe and Morehart (2012) utilized three years of ARMS data and the propensity score matching regression technique to control for the endogeneity of adoption decisions of risk management tool on farm profit. Findings indicated, among others, that the adoption of input price risk management practice improves farm-level profits by 13-17 percent.

\section{Empirical Estimation}

Allowing an index $R$ to represent the number of risk management strategies used by the farm operator, the likelihood of a favorable economic position of the jth farm household (i.e., low-income, high-wealth; high-income, low-wealth; and high-income, high-wealth) relative to a disadvantageous position (i.e., low-income, low-wealth) is represented by a latent variable $I^{*}$ as in:

$$
\begin{aligned}
I_{j}^{*} & =\beta_{0}+\sum_{k=1}^{K-1} \beta_{k}^{\prime} X_{j, K-1}+\beta_{K}^{\prime} R_{j, K}+\varepsilon_{j}=\beta^{\prime} X_{j}+\varepsilon_{j}, \quad \varepsilon_{j} \sim N(0,1) \\
I_{j} & =1 \quad \text { if } I_{j}^{*} \succ 0 \text { (household in favorable income and wealth category), } \\
& =0 \quad \text { if } I_{j}^{*} \leq 0 \text { (otherwise), }
\end{aligned}
$$

where $X$ is a vector of explanatory variables, and $\beta$ is a vector of parameters to be estimated. The elements in $X$ include, among others, variables reflecting characteristics of the operator, the household, the farm, and the off-farm labor market areas. To the extent that the index $R$ might be endogenous, estimation of (1) without attending to this concern could result in inconsistent and biased parameter estimates. ${ }^{6}$ To circumvent this problem, a two-stage residual inclusion method, as proposed by Terza, Basu, and Rathouz (2008), is used.

\subsection{First Stage Estimation}

Let the discrete index $R_{j}$ denoting the number of risk management strategies utilized by the $\mathrm{j}^{\text {th }}$ operator be represented by the following model: ${ }^{7}$

$$
R_{j}=x_{j}^{\prime} \gamma+v_{j}, \quad j=(1, \ldots, n),
$$

where $x$ is a set of strictly exogenous variables with elements that exceed in numbers those in $X$ as described in (1). Equation (2) includes an 'exclusion restriction' variable which is needed for model's identification. Two count regression models are considered in the estimation of (2): ${ }^{8}$

\subsubsection{Poisson Regression Model}

This model, which is also known as a log-linear model, specifies that each element $r$ of the discrete vector $R$ is drawn from a Poisson distribution with a conditional mean $\eta$. The elements $r_{i}$ and $r_{l}$ of $R$, which are independent and identically distributed for any $i \neq l$, are related to the covariates $x_{j}$ as in (see Greene, 2008; p. 906-907) the following probability representation:

$$
\begin{aligned}
\text { Prob }\left(R_{j}\right. & \left.=r_{j} \mid x_{j}, \eta_{\mathrm{i}}\right)=f\left(r_{j} ; \eta_{j}\right)=\frac{\exp \left(-\eta_{j}\right) \eta_{j}^{r_{j}}}{r_{j} !}, r=0,1,2, \ldots, \text { with } \\
\eta_{j} & =E\left(R_{j}\right)=\operatorname{Var}\left(R_{j}\right)=\exp \left(x_{j}^{\prime} \gamma\right), \text { and } \\
\log \eta_{j} & =x_{j}^{\prime} \gamma,
\end{aligned}
$$

where $x_{j}^{\prime}$ is a $[1 \times(k+1)]$ vector of explanatory variables of the $j^{\text {th }}$ observation, and $\gamma$ is a $[(k+1) \times 1]$ vector of regression coefficients. Equation (3) indicates that the expected number of risk management strategies utilized by the farmer is equal to the variance of the distribution of $r_{j}$. In the context of this paper, this property of the Poisson

\footnotetext{
${ }^{6}$ Endogeneity might arise here due to the possibility that some of the omitted and unobserved confounders (e.g., degree of risk aversion, soil quality, local environmental restrictions, etc.) are correlated with both the predictor variable $R$ and the discrete outcome measure I. Kuethe and Morehart (2012) noted, for example, that when the likelihood of adopting a risk management strategy is directly related to the farm's economic position (e.g., net farm income), operations with certain characteristics may be more likely to implement risk management tools; hence the possibility of endogeneity exits in attempts to regress economic measures on covariates that include the adoption of certain risk management tools.

${ }^{7}$ The maximum number of risk management strategies that $R$ represents, which will be expounded upon later in the paper, is five.

${ }^{8}$ The exclusion restriction variable used, as will be discussed in detail in the result section of the paper, is an indicator variable denoting whether the primary occupation of the operator is 'farming/ranching', a variable that is correlated with the endogenous variable $R$ in (2) but not with the outcome variable $I$ in (1).
} 
regression, called 'equi-dispersion', is restrictive. This is because one is likely to find the variance of $r$, particularly in the presence of zeros (i.e., when no risk management strategy was used by the farmer) in $R$, different than the mean of $r_{j}$. When the variance of $r_{j}$ is larger (smaller) than the mean, this indicates the presence of 'over-dispersion' (under-dispersion) in the underlying data.

\subsubsection{Zero-Inflated Poisson Regression Model}

As derived by Lambert (1992), this model differs from the one described in (3) by allowing for abundance of zero counts. Specifically, a count of only zero $\left(r_{j}=0\right.$; or regime 1 with probability $\left.=p_{j}\right)$ is assumed to be generated by a process that differs from a Poisson process that produces an alternative count $\left(r_{j}>0\right.$; or regime 2 with probability $=1-$ $p_{j}$ ) so that: ${ }^{9}$

$$
\operatorname{Pr}\left(r_{j} \mid x_{j}\right)=\left\{\begin{array}{ll}
p_{j}+\left(1-p_{j}\right) \exp \left(-\eta_{j}\right) & \text { for } r_{j}=0 ; j=(1,2, \ldots, n) \\
\left(1-p_{j}\right) \frac{\exp \left(-\eta_{j}\right) \eta_{j}^{r_{j}}}{r_{j} !} & \text { for } r_{j}>0 ; r=1,2,3, \ldots
\end{array}\right\},
$$

where, as in the standard Poisson model, $\eta_{\mathrm{i}}=\exp \left(x_{i}^{\prime} \gamma\right)$. The link function that relates $\eta=\left(\eta_{1}, \ldots, \eta_{n}\right)$ and $p=\left(p_{1}, \ldots, p_{n}\right)$ to the determinants of the index $R$ can be written as:

$$
\begin{aligned}
\log \eta_{j} & =x_{j}^{\prime} \gamma, \text { and } \\
p_{j} & =F\left(z_{j}^{\prime} \varphi\right),
\end{aligned}
$$

where $F($.$) is a cumulative distribution function, \varphi$ is a vector of parameters to be estimated by either a logit or a probit regression, and $z_{j}$ is a vector of covariates describing farm operator's characteristics that can be the same as in $x_{j}$ in (3) or a subset of $x_{j}$.

The conditional mean and the variance of the distribution in (4) are (see Long, 1997, p. 243; Sorensen, 1999):

$$
\begin{aligned}
E\left(r_{j} \mid x_{i}\right) & =\left[(0) p_{j}+\left(1-p_{j}\right) E\left(r_{j}^{*} \mid x_{j}, r_{j}^{*}>0\right)\right]=\left(1-p_{j}\right) \eta_{j}, \text { and } \\
\operatorname{Var}\left(r_{j} \mid x_{j}\right) & =\eta_{j}\left(1-p_{j}\right)\left(1+\eta_{j} p_{j}\right),
\end{aligned}
$$

where $r^{*}$ denotes the outcome of the Poisson process in regime 2. Equation (6) allows for over-dispersion in the data when $p_{j}$ is not zero.

\subsection{Second Stage Estimation}

Determination of which of the two count regression models to implement in testing and/or correcting for the endogeneity of the index $R$ in (1) is based on testing the validity of the 'equi-dispersion' assumption of the Poisson model. Once determined, the 'raw' residual (i.e., the difference between the actual response and the value estimated by the regression model) of the chosen model will be included along with the vector $R$ in (1). A $t$-test of the hypothesis that the coefficient of the estimated residual $\hat{v}$ equals zero is a test of the exogeneity of $R$ (see Terza, Basu, and Rathouz 2008), and failure to include $\hat{v}_{j}$ in (1) based on a rejection of this hypothesis will yield inconsistent and biased parameter estimates. Accordingly, the revised regression model described in (1) becomes:

$$
\begin{aligned}
& I_{j}^{*}=\beta_{0}+\sum_{k=1}^{K-1} \beta_{k}^{\prime} X_{j, K-1}+\beta_{K}^{\prime} R_{j, K}+\hat{v}_{j, K+1}+\varepsilon_{j}=\beta^{\prime} X_{J}+\varepsilon_{J}, \text { where } \\
& \varepsilon_{j} \approx \operatorname{MVN}(0, \Sigma), \text { for } j=1, \cdots, n .
\end{aligned}
$$

The expected value of $I_{j}$ in (7) represents the probability $(P)$ of the jth farm household falling in any one of the considered $M$ income-wealth categories relative to an excluded category. To the extent that (7) assumes that the effect of $R$ on $P$ is linear and uniform across all of the possible numbers of the risk-management strategies utilized as described in $R$, which may not be the case even after correcting for the potential that it is endogenous, the analysis considers a probability-based model where such an effect is allowed to be nonlinear as in (with subscript $j$ suppressed). Specifically, the possibility for such a nonlinear impact is incorporated in the regression model by defining a set of dummy variables, $D_{N}(N=1,2, \ldots, 5)$ where each one of these variables denoting the number of risk management strategies used by the

\footnotetext{
${ }^{9}$ Many studies related to agricultural production have applied this type of regression model (see El-Osta 2007; Artolini, Andreoli, and Brunori 2014; Cai, Guanming, and Hu 2016; among others).
} 
farmer as in ${ }^{10}$ :

$$
I^{*}=\beta_{0}+\sum_{k=1}^{K-1} \beta_{k}^{\prime} X_{K-1}+\sum_{K=1}^{N} \beta_{K}^{\prime} D_{N}+\hat{v}_{N+1}+\varepsilon=\beta^{\prime} X+\varepsilon .
$$

The probability that the $\mathrm{j}$ th farm household's economic outcome falls in the $s^{\text {th }}$ category and not in the $q^{\text {th }}$ category of the income-wealth indicator $I$ is captured by the $P_{s j}$ using multinomial probit $(M N P$ ) regression (see Daganzo, 1979; Bunch 1991; Cooper 2003; El-Osta 2014): ${ }^{11}$

$$
\begin{aligned}
P_{s j} & =\operatorname{Pr}(I=s \mid \beta, X, \Sigma)=\operatorname{Pr}\left\{\varepsilon_{s j}-\varepsilon_{q j} \leq\left(X_{q j}-X_{s j}\right)^{\prime} \beta\right\}, \quad s \neq q, \text { for } s=1, \cdots, M-1 \\
& =\int_{-\infty}^{\beta_{1}^{\prime} X_{1}} \cdots \int_{-\infty}^{\beta^{\prime}{ }_{M-1} X_{M-1}} f\left(\varepsilon_{1}, \cdots, \varepsilon_{M-1}\right) d \varepsilon_{1} \cdots d \varepsilon_{M-1},
\end{aligned}
$$

where $\beta$ is $(K+1) \mathrm{x} 1$ or $(L+1) \mathrm{x} 1$ vector of parameters to be estimated based on (7) or (8), respectively, $\varepsilon$ is $(M-1) \mathrm{x} 1$ vector of random disturbances that are multivariate normally distributed, $\sum$ is a $(M-1) \mathrm{x}(M-1)$ positive definite covariance matrix, and $f($.$) is the probability density function of the multivariate standard normal distribution.$

\section{Data}

The main data source is the 2015 ARMS. The ARMS, which has a complex stratified, multiframe design, is a national survey conducted annually by the National Agricultural Statistics Service (NASS) and the Economic Research Service (see https://www.ers.usda.gov/data-products/arms-farm-financial-and-crop-production-practices/arms-data/). Each observation in the ARMS represents a number of similar farms (e.g., based on land use, size of farm, etc.), the particular number being the survey expansion factor (or the inverse of the probability of the surveyed farm being selected for surveying), and is referred to henceforth as survey weight $w_{j}(j=1, \ldots, n)$.

As shown in Table 1, which also lists the summary statistics and definition of all the variables used in the analysis, the size of the full sample in 2015 was 16,683 , which when properly expanded using survey weights resulted in a population of U.S. farms totaling 2,031,660 located across the lower forty eight states. Auxiliary data on climate indicators relevant to county-specific cropping areas and on labor market conditions as represented by the county unemployment rates were also used. ${ }^{12}$ Table 1 shows that farmers in economic categories with higher wealth (i.e., columns 2 and 4), and relative to their counterparts in the least economically advantageous category with lower income and lower wealth (i.e., column 1), tend to have more operators who are aged 55 or older, have higher levels of accumulated farm capital, and are more likely to operate larger-sized farms.

\footnotetext{
${ }^{10} \mathrm{~A}$ study by Lochner and Moretti (2015) points out that models as described in (7) and (8), even when endogeneity is not present, can lead to different parameter estimates when estimation is based on OLS regression and when (7) is wrongly presumed to be the correct specification of the regression model when in fact the true specification is described in (8). The limitation of estimating (8) in the context of this paper when the 5 potentially endogenous dummy variables $\left(D_{l}\right)$ representing the possible non-linear impact of the possible counts of the risk management strategies on $I$ is that finding a number of valid instruments (at least one for each of the $D \mathrm{~s}$ ) is not practical. A caveat hence is in order here. To the extent that the same instrument is used in the first stage of estimating both (7) and (8) due to the difficulty in finding valid instruments for the potentially endogenous dummy variables $\left(D_{l}\right)$ may possibly yield different parameter estimates of $D_{l}$.

${ }^{11}$ The benefit of using $M N P$ over multinomial logit $(M N L)$ regression is that the variance-covariance matrix $\sum$ in $M N P$ allows for possible correlation among the $M$ income-wealth categories. This is important as the same farmer can fall in one particular economic performance category in one year and in another one in the next year, thus the use of $M N P$ allows for the avoidance of the need to satisfy the restrictive assumption of independence of irrelevant alternatives, or independence of the errors across equations, as required by $M N L$ (for more detail, see Train 2003).

${ }^{12}$ Climate data were provided by Ryan Williams, Economic Research Service, USDA. The source for unemployment rates was the 2015 Local Area Unemployment Statistics (Bureau of Labor Statistics) file.
} 
Table 1. Summary statistics of variables used in Poisson, zero-inflated Poisson, and multinomial probit regression models of use of 'risk management strategies' and of 'economic performance', 2015

\begin{tabular}{|c|c|c|c|c|c|}
\hline \multirow[b]{2}{*}{ Item } & \multicolumn{4}{|c|}{ 'Economic performance' } & \multirow[b]{2}{*}{$\begin{array}{l}\text { All farm } \\
\text { operator } \\
\text { households }\end{array}$} \\
\hline & $\begin{array}{l}\text { (1) } \\
\text { Low-income, } \\
\text { low-wealth }\end{array}$ & $\begin{array}{l}\text { (2) } \\
\text { Low-income, } \\
\text { high-wealth }\end{array}$ & $\begin{array}{l}\text { (3) } \\
\text { High-income, } \\
\text { low-wealth }\end{array}$ & $\begin{array}{l}\text { (4) } \\
\text { High-income, } \\
\text { high- wealth }\end{array}$ & \\
\hline \multicolumn{6}{|l|}{ Dependent variable: } \\
\hline Number of risk management strategies & 1.66 & 2.44 & 2.07 & 2.60 & 2.17 \\
\hline Economic performance indicator $(\%)$ & 33.46 & 16.43 & 16.52 & 33.59 & 100.00 \\
\hline \multicolumn{6}{|l|}{ Explanatory variables: } \\
\hline \multicolumn{6}{|l|}{ Operator, household, and farm characteristics: ${ }^{1}$} \\
\hline $35<=$ age $<45$ & 0.06 & 0.03 & 0.18 & 0.05 & 0.07 \\
\hline $45<=$ age $<55$ & 0.14 & 0.10 & 0.31 & 0.13 & 0.16 \\
\hline $55<=$ age $<65$ & 0.36 & 0.29 & 0.28 & 0.43 & 0.35 \\
\hline $65<=$ age & 0.38 & 0.56 & 0.14 & 0.37 & 0.37 \\
\hline Education: college and beyond (1/0) & 0.16 & 0.25 & 0.35 & 0.41 & 0.29 \\
\hline Race: white $(1 / 0)$ & 0.84 & 0.93 & 0.93 & 0.93 & 0.90 \\
\hline Gender: male $(1 ; 0)$ & 0.86 & 0.90 & 0.88 & 0.90 & 0.88 \\
\hline Marital status: married (1/0) & 0.68 & 0.76 & 0.88 & 0.87 & 0.79 \\
\hline Occupation: hired manager (1/0) & 0.30 & 0.14 & 0.71 & 0.44 & 0.39 \\
\hline Size of farm household $(1 / 0)$ & 2.39 & 2.23 & 3.02 & 2.49 & 2.50 \\
\hline Farm organization: sole proprietor $(1 / 0)$ & 0.94 & 0.89 & 0.92 & 0.84 & 0.90 \\
\hline Farm organization: partnership (1/0) & 0.04 & 0.06 & 0.05 & 0.08 & 0.06 \\
\hline Farm organization: family corporation $(1 / 0)$ & 0.00 & 0.01 & 0.01 & 0.02 & 0.01 \\
\hline Farm tenure: full owner $(1 / 0)$ & 0.71 & 0.64 & 0.64 & 0.63 & 0.66 \\
\hline Type of farm: cash grains $(1 / 0)$ & 0.05 & 0.16 & 0.09 & 0.15 & 0.11 \\
\hline Type of farm: fruits and vegetables $(1 / 0)$ & 0.07 & 0.08 & 0.08 & 0.10 & 0.08 \\
\hline Type of farm: dairy $(1 / 0)$ & 0.02 & 0.04 & 0.01 & 0.03 & 0.02 \\
\hline Type of farm: beef and hogs $(1 / 0)$ & 0.42 & 0.37 & 0.39 & 0.34 & 0.38 \\
\hline Previous year's sales: 50-250 (\$1,000) $(1 / 0)$ & 0.09 & 0.26 & 0.12 & 0.21 & 0.16 \\
\hline Previous year's sales: $250-500(\$ 1,000)(1 / 0)$ & 0.01 & 0.07 & 0.03 & 0.07 & 0.04 \\
\hline Previous year's sales: 500 or more $(\$ 1,000)(1 / 0)$ & 0.01 & 0.09 & 0.04 & 0.13 & 0.07 \\
\hline Farm capital $(\$ 1,000)$ in $2015 /$ years farming & 5.58 & $16.52^{*}$ & $10.48^{*}$ & $14.16^{*}$ & 11.07 \\
\hline Farm location: metro county $(1 / 0)$ & 0.38 & 0.38 & 0.44 & 0.43 & 0.41 \\
\hline \multicolumn{6}{|l|}{ County characteristics: ${ }^{2}$} \\
\hline County unemployment rate $(\%)$ & 5.56 & $5.13^{*}$ & 5.47 & $5.13^{*}$ & 5.33 \\
\hline County annual precipitation (Inches) & 47.33 & $42.88^{*}$ & 45.45 & $43.30^{*}$ & 44.93 \\
\hline County average temperature (Fahrenheit) & 44.07 & $42.16^{*}$ & 43.69 & $43.06^{*}$ & 43.36 \\
\hline \multicolumn{6}{|l|}{ Exclusion restriction variable: } \\
\hline Primary occupation: farming/ranching (1/0) & 0.48 & 0.65 & 0.23 & 0.43 & 0.45 \\
\hline Sample size & 3,323 & 4,088 & 1,950 & 7,322 & 16,683 \\
\hline Expanded number of farms & 679,797 & 333,740 & 335,682 & 682,440 & $2,031,660$ \\
\hline
\end{tabular}

${ }^{1}$ Source: 2015 Agricultural Resource Management Survey (Version 1, Phase III). ${ }^{2}$ Source: Unemployment rates were obtained from the Bureau of Labor Statistics. Note: The standard deviations of estimates of all continuous variables were estimated based on Jackknife variance estimation method with 30 replicate samples. Differences in the means of these estimates in the second, third, and fourth 'Economic performance' categories and those in the first category (i.e., 'Low-income, lower-wealth', which indicates economic disadvantage) are denoted with * indicating that the respective means within each row were statistically different (at 5\% level confidence interval) from the means in the first category.

\section{Results}

The analysis considered five risk management strategies that can be used by the farm operator, either singly or in combination with other strategies, for the purpose of protecting against adverse economic outcomes. These strategies include utilization of diversified farming practices; purchasing of crop insurance coverage; having part or all of total value of crop or livestock production under contract; utilization of professional or farm management services such as record keeping, accounting, tax and business planning, farm product advice, conservation practices, etc.; and spending on custom work such as renting or leasing of tractors, vehicles, equipment or storage structures, and hauling of hauling 
of grain, livestock, milk, etc. ${ }^{13}$ Table 2 shows that the use of professional advice, custom work, and diversified farming were the most popular strategies adopted by farmers to mitigate risk in farm production.

Table 2. Distribution of types of risk management strategies utilized by number of strategies, $2015^{1}$

\begin{tabular}{llllllll}
\hline Strategies & Zero & One & Two & Three & Four & All five & All households \\
\hline Farm diversification & 0 & 0.16 & 0.47 & 0.76 & 0.97 & 1.00 & 0.25 \\
Crop insurance & 0 & 0.04 & 0.22 & 0.63 & 0.97 & 1.00 & 0.16 \\
Production contracts & 0 & 0.01 & 0.05 & 0.06 & 0.08 & 1.00 & 0.02 \\
Professional advice & 0 & 0.58 & 0.73 & 0.86 & 0.99 & 1.00 & 0.43 \\
Custom work & 0 & 0.21 & 0.54 & 0.69 & 0.98 & 1.00 & 0.27 \\
\hline
\end{tabular}

Source: 2015 ARMS (Version 1, Phase III).

Note: With the exception of when one risk management strategy was used, the sum of the proportions across all possible type of strategies needs not add up to 1 .

${ }^{1} R=\sum_{q=0}^{5} r_{q}$.

Figure 2 shows a histogram of the relative weighted frequencies of the five risk management strategies as represented by the index $R$ as shown in equation (2). The figure shows the distribution of the index $R$ to be positively skewed. At one extreme, the figure also shows 38.6 percent of farmers with a zero rate of adoption of risk management tools, to 0.2 percent of the operators reporting use of all of the five strategies considered. Because the index $R$ is discrete with censoring at zero, and its distribution is skewed, the distribution of the error terms $v_{j}$ is no longer homoscedastic or normal (Blundell et al., 1995) which makes the count regression model the preferred technique to use in the estimation of equation (2) in place of a standard multiple linear regression counterpart.

Table 3 provides the results of the first stage of estimating the determinants of economic performance of farm households using two count regression models; a Poisson and a zero-inflated Poisson regression (ZIP) model. ${ }^{14}$ Since the weighted variance of the index $R$ is larger than its weighted mean (1.40 versus 1.13, respectively), the zero-inflated Poisson regression model is deemed as the more appropriate model to use in the analysis than the standard Poisson model. ${ }^{15}$

\footnotetext{
${ }^{13}$ Diversified farm production by the operator is defined based on whether the farmer is in the top quartile of the entropy index (see Theil 1971). Specifically, by letting $q_{j}$ represent the percent of value of production from enterprise $\mathrm{j}$, the extent of diversification of farm production among $N$ possible enterprises is measured as:

Entrop $y_{\mathrm{i}}=\sum_{j=1}^{N}\left(q_{j}\right) \frac{\log \left[\frac{1}{\left(q_{j}\right)}\right]}{\log (\mathrm{N})}$,

where the index ranges from $0 \%$ (i.e., a completely specialized farm producing only one commodity) to $100 \%$ (i.e., a completely diversified farm with equal shares of each commodity).

${ }^{14}$ The Poisson and the zero-inflated Poisson regression models were estimated in Stata, respectively, using the poisson and zip regression commands (StataCorp 2015).

${ }^{15}$ A Vuong likelihood ratio test (Vuong 1989), which compares the zero-inflated Poisson model with an ordinary Poisson regression model, was performed on the raw sample. Result based on the statistical significance of the test indicated the superiority of the zero-inflated model $(\mathrm{z}=8.27 ; \operatorname{Pr}>\mathrm{z}=0.0000)$.
} 


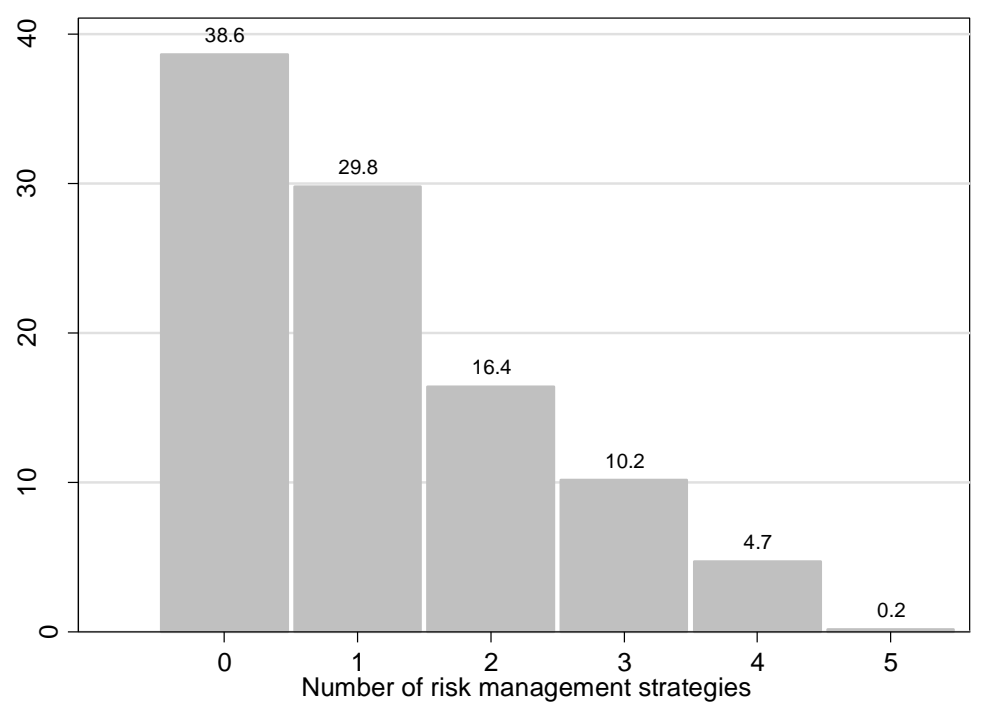

Figure 2. Relative frequency distribution of number of risk management strategies, 2015

The results from the ZIP regression estimation showed that the exclusion restriction variable used (i.e., when the primary occupation of the farmer was farming/ranching) was highly correlated, as required in terms of using valid instruments, with the endogenous variable $R \cdot{ }^{16}$ Findings indicated that farmers who are white, and those who work on the farm as hired managers tend to adopt more risk management strategies on their farming operation. In contrast, farmers who fully own their farmland are found with a sizeable lesser usage of risk management strategies than those farmers who partially own their land or who are full renters.

In terms of factors with the most impact on the expected number of strategies used by farm operators, results from the ZIP model showed size of the farming operation based on a previous year's farm sales, particularly when farm size is the largest, tend to have the biggest influence. ${ }^{17}$ For example, the expected number of risk management strategies adopted by farms with sales of at least $\$ 500,000$, while holding all other variables constant, are larger than the number used by farms with lower sales by $119 \%$ (i.e., by $100[\exp (0.785)-1])$. The results of the estimated coefficients from the 'probit' regression part of the ZIP model, which estimates the likelihood of a 'zero' number of risk management strategies (i.e., the chance of belonging to the excess zero-generating process), show that the log of odds of such an occurrence decreases significantly with a larger farm size and a higher level of farm capital. ${ }^{18}$

\footnotetext{
${ }^{16} \mathrm{An}$ additional test to affirm the validity of this instrument (i.e., dummy variable representing 'farming/ranching' as the primary occupation of the farm operator) was conducted and it was found not to be correlated with the outcome variable (i.e., as proxied by 3 dummy variables representing advantageous economic performance categories as depicted in Figure 1 relative to a category of 'low-income, low-wealth').

${ }^{17} \mathrm{~A}$ stronger impact of farm size on the expected number of adopted risk management strategies was found in the less desirable Poisson regression model.

${ }^{18}$ To the extent that there is no theory to guide in the selection of variables in the 'probit' regression part of the ZIP, variables are chosen in the analysis based on general synthesis of related literature of what might impact the decision of the farmer to adopt (or not to adopt) any of the risk management strategies considered.
} 
Table 3. Weighted Poisson and zero-inflated Poisson regression estimates of number of risk management strategies adopted by farmers: 2015

\begin{tabular}{|c|c|c|c|c|}
\hline \multirow[b]{3}{*}{ Variables } & \multicolumn{2}{|l|}{ Poisson } & \multicolumn{2}{|l|}{ ZIP } \\
\hline & $\hat{\gamma}$ & Standard & $\hat{\gamma}$ & Standard \\
\hline & & errors & & errors \\
\hline Constant & -0.3600 & 0.1417 & -0.0322 & 0.1193 \\
\hline $35<=$ age $<45$ & -0.0431 & 0.0538 & -0.0322 & 0.0520 \\
\hline $45<=$ age $<55$ & -0.0408 & 0.0980 & -0.0291 & 0.0539 \\
\hline $55<=$ age $<65$ & $-0.1062^{* *}$ & 0.0500 & -0.0672 & 0.0478 \\
\hline $65<=$ age & -0.0563 & 0.0668 & -0.0486 & 0.0483 \\
\hline Education: college and beyond & 0.0281 & 0.0329 & 0.0280 & 0.0346 \\
\hline Race: white & $0.3353^{* *}$ & 0.1593 & $0.2332^{* * *}$ & 0.0550 \\
\hline Gender: male & -0.0791 & 0.0804 & -0.0699 & 0.0713 \\
\hline Marital status: married & 0.0285 & 0.1043 & 0.0076 & 0.0281 \\
\hline Occupation: hired manager & 0.2946 & 0.2064 & $0.2216^{* *}$ & 0.0827 \\
\hline Size of farm household & 0.0046 & 0.0112 & 0.0058 & 0.0108 \\
\hline Farm organization: sole proprietor & -0.0219 & 0.1148 & -0.0041 & 0.0360 \\
\hline Farm organization: partnership & 0.0711 & 0.0974 & 0.0773 & 0.0485 \\
\hline Farm organization: family corporation & 0.0206 & 0.1413 & 0.0309 & 0.0535 \\
\hline Farm tenure: full owner & $-0.2458^{* * *}$ & 0.0372 & $-0.2081^{* * *}$ & 0.0345 \\
\hline Type of farm: cash grains & $0.4008^{* * *}$ & 0.1222 & $0.3626^{* * *}$ & 0.0254 \\
\hline Type of farm: fruits and vegetables & -0.0494 & 0.1824 & -0.0590 & 0.0632 \\
\hline Type of farm: dairy & $0.3768^{* * *}$ & 0.0994 & $0.3415^{* * *}$ & 0.0326 \\
\hline Type of farm: beef and hogs & 0.0945 & 0.1073 & 0.0483 & 0.0365 \\
\hline Previous year's sales: 50-250 (\$1,000) & $0.7217^{* * *}$ & 0.0518 & $0.6213^{* * *}$ & 0.0335 \\
\hline Previous year's sales: $250-500(\$ 1,000)$ & $0.8338^{* * *}$ & 0.0444 & $0.7340^{* * *}$ & 0.0445 \\
\hline Previous year's sales: 500 or more $(\$ 1,000)$ & $0.8790^{* * *}$ & 0.0412 & $0.7850^{* * *}$ & 0.0440 \\
\hline Farm capital $(\$ 1,000)$ in 2015 / years farming & $0.0002^{* *}$ & 0.0001 & 0.0002 & 0.0001 \\
\hline Farm location: metro county & -0.0477 & 0.0507 & -0.0488 & 0.0298 \\
\hline County unemployment rate & $-0.0277^{*}$ & 0.0138 & $-0.0318^{* * *}$ & 0.0084 \\
\hline County annual precipitation (Inches) & 0.0019 & 0.0013 & 0.0013 & 0.0012 \\
\hline County average temperature (Fahrenheit) & -0.0063 & 0.0045 & $-0.0069^{* *}$ & 0.0027 \\
\hline \multirow[t]{3}{*}{ Occupation: farming/ranching (instrument) } & $0.4375^{* * * *}$ & 0.0857 & $0.3654^{* * *}$ & 0.0721 \\
\hline & & & \multicolumn{2}{|l|}{ Probit } \\
\hline & & & $\hat{\varphi}$ & $\begin{array}{c}\text { Standard } \\
\text { errors }\end{array}$ \\
\hline Constant & & & -0.6688 & 0.4562 \\
\hline $65<=$ age & & & -0.3469 & 0.3209 \\
\hline Education: college and beyond & & & 0.0658 & 0.3639 \\
\hline Occupation: hired manager & & & -0.1515 & 0.3404 \\
\hline Farm organization: sole proprietor & & & 0.3145 & 0.3554 \\
\hline Farm tenure: full owner & & & 0.5157 & 0.4950 \\
\hline Type of farm: dairy & & & -1.0498 & 2.6977 \\
\hline Previous year's sales: 50-250 $(\$ 1,000)$ & & & -1.7834 & 10.3972 \\
\hline Previous year's sales: $250-500(\$ 1,000)$ & & & $-7.5416^{*}$ & 3.8319 \\
\hline Previous year's sales: $250-500(\$ 1,000)$ & & & $-7.0253^{* *}$ & 3.9018 \\
\hline Farm capital $(\$ 1,000)$ in 2015 / years farming & & & $-0.9263^{* * *}$ & 0.2758 \\
\hline Farm location: metro county & & & 0.0551 & 0.2149 \\
\hline
\end{tabular}

Notes: Statistical significance for the estimated coefficients of the regression models are based on Jackknife standard errors with 30 replicate samples [for more detail, see Dubman (2000)], with ${ }^{*} p<0.10,{ }^{* *} p<0.05$, and ${ }^{* * *} p<0.01$.

Results in Table 4 show that the estimated coefficients of the vectors of 'raw' residuals from the ZIP regression model are statistically significant $(p<0.01)$ in the 'low-income, high-wealth' categories in both of the $M N P$-based economic performance regression models as in (7) and (8). The finding with regard to these significant coefficients hence supports the incorporation of these 'correction' vectors in the regressions as a means of purging the endogenous risk management strategy variables in the 'low-income, high-wealth' categories in both models. In contrast, the finding of statistically insignificant coefficients of the vectors of residuals in the other two categories (i.e., 'high-income, low-wealth' and 'high-income, high-wealth') in the MNP model, indicates that the use of the determinants capturing risk management strategies as exogenous, either in the form of the discrete index $R$ or as dummy variables, is appropriate. As evident 
from the results in Table 4, the estimated coefficients of the vectors of residuals across the two models that are separated only by how risk management strategies are modeled in (7) and (8) are quite similar.

Table 4. Multinomial probit parameter estimates of factors impacting the economic performance of farm households, $2015^{1}$

\begin{tabular}{|c|c|c|c|c|c|c|}
\hline \multirow[b]{2}{*}{ Variables } & \multicolumn{3}{|c|}{ Economic performance (eq. 7) } & \multicolumn{3}{|c|}{ Economic performance (eq. 8) } \\
\hline & $\begin{array}{l}\text { Low- income, } \\
\text { high- wealth }\end{array}$ & $\begin{array}{l}\text { High- } \\
\text { income, } \\
\text { low- } \\
\text { wealth }\end{array}$ & $\begin{array}{l}\text { High- } \\
\text { income, } \\
\text { high- } \\
\text { wealth }\end{array}$ & $\begin{array}{l}\text { Low- income, } \\
\text { high- wealth }\end{array}$ & $\begin{array}{l}\text { High- } \\
\text { income, } \\
\text { low- } \\
\text { wealth }\end{array}$ & $\begin{array}{l}\text { High- } \\
\text { income, } \\
\text { high- } \\
\text { wealth }\end{array}$ \\
\hline Constant & $-3.7566^{* * *}$ & $-2.1972^{* * *}$ & $-3.8931^{* * *}$ & $-3.7410^{* * * *}$ & $-2.2391^{* * *}$ & $-3.8889^{* * *}$ \\
\hline $35<=$ age $<45$ & 0.5651 & 0.3679 & $1.1223^{* * *}$ & 0.5686 & 0.3690 & $1.1195^{* * *}$ \\
\hline $45<=$ age $<55$ & 1.0448 & 0.3335 & $1.5169^{* * *}$ & 1.0509 & 0.3393 & $1.5156^{* * *}$ \\
\hline $55<=$ age $<65$ & $1.4835^{* * *}$ & -0.0444 & $2.1951^{* * * *}$ & $1.4906^{* * *}$ & -0.0397 & $2.1959^{* * *}$ \\
\hline $65<=$ age & $1.9298^{* * * *}$ & -0.2679 & $2.2908^{* * * *}$ & $1.9338^{* * * *}$ & -0.2636 & $2.2897^{* * *}$ \\
\hline Education: college and beyond & $0.4241^{* * *}$ & $0.6367^{* * *}$ & $0.9582^{* * * *}$ & $0.4180^{* * * *}$ & $0.6380^{* * *}$ & $0.9573^{* * * *}$ \\
\hline Race: white & 0.2335 & 0.0164 & 0.1663 & 0.2424 & 0.0194 & 0.1652 \\
\hline Gender: male & 0.1287 & 0.0484 & 0.1034 & 0.1171 & 0.0485 & 0.1013 \\
\hline Marital status: married & 0.1913 & $0.7986^{* *}$ & $0.7563^{* * *}$ & 0.1897 & $0.8049^{* *}$ & $0.7581^{* * * *}$ \\
\hline Occupation: hired manager & -0.2984 & $1.1181^{* * * *}$ & $0.9856^{* * *}$ & -0.2969 & $1.1166^{* * * *}$ & $0.9871^{* * * *}$ \\
\hline Size of farm household & -0.0479 & -0.0088 & -0.0255 & -0.0498 & -0.0069 & -0.0270 \\
\hline Farm organization: sole proprietor & -0.0663 & -0.0853 & -0.2241 & -0.0851 & -0.0658 & -0.2294 \\
\hline Farm organization: partnership & -0.0898 & -0.2483 & -0.1745 & -0.1100 & -0.2378 & -0.1809 \\
\hline Farm organization: family corporation & $0.5577^{*}$ & $0.9417^{* * *}$ & 0.6740 & $0.5585^{*}$ & $0.9616^{* * *}$ & 0.6800 \\
\hline Farm tenure: full owner & $0.5061^{* * *}$ & 0.0301 & 0.2815 & $0.5245^{* * *}$ & 0.0177 & 0.2888 \\
\hline Type of farm: cash grains & -0.3357 & -0.1005 & -0.1278 & -0.3626 & -0.0901 & -0.1378 \\
\hline Type of farm: fruits and vegetables & 0.0071 & -0.0264 & -0.0761 & 0.0146 & -0.0392 & -0.0757 \\
\hline Type of farm: dairy & -0.4008 & -0.4955 & -0.1605 & -0.4398 & -0.4838 & -0.1875 \\
\hline Type of farm: beef and hogs & 0.0857 & -0.0822 & -0.0515 & 0.0967 & -0.0903 & -0.0482 \\
\hline Previous year's sales: $50-250(\$ 1,000)$ & 0.3262 & 0.2947 & 1.0240 & 0.3136 & 0.3138 & $1.0133^{*}$ \\
\hline Previous year's sales: $250-500(\$ 1,000)$ & 0.5085 & $0.8380^{* * *}$ & $1.7688^{* *}$ & 0.4738 & $0.8623^{* * *}$ & $1.7522^{* * *}$ \\
\hline Previous year's sales: 500 or more $(\$ 1,000)$ & 0.5939 & $1.0543^{* * *}$ & $2.2110^{* * * *}$ & 0.5557 & $1.0913^{* * *}$ & $2.2094^{* * * *}$ \\
\hline Farm capital $(\$ 1,000)$ in $2015 /$ years farming & 0.0051 & 0.0025 & 0.0043 & 0.0051 & 0.0025 & 0.0043 \\
\hline Farm location: metro county & 0.0840 & 0.1184 & 0.0885 & 0.0807 & 0.1179 & 0.0862 \\
\hline County unemployment rate & $-0.0488^{*}$ & -0.0178 & $-0.0853^{* * *}$ & -0.0485 & -0.0170 & $-0.0863^{* * *}$ \\
\hline County annual precipitation (Inches) & -0.0075 & -0.0090 & -0.0106 & -0.0077 & -0.0092 & -0.0106 \\
\hline County average temperature (Fahrenheit) & 0.0030 & 0.0103 & $0.0127^{*}$ & 0.0039 & 0.0101 & $0.0129^{*}$ \\
\hline Number of risk management strategies & $1.2937^{* * *}$ & 0.3080 & 0.4884 & -- & -- & -- \\
\hline Number of risk management strategies $=1$ & -- & -- & -- & $1.1575^{* *}$ & 0.4187 & 0.4623 \\
\hline Number of risk management strategies $=2$ & -- & -- & -- & $2.5675^{* * *}$ & 0.5417 & 1.0098 \\
\hline Number of risk management strategies $=3$ & -- & -- & -- & $4.0278^{* * * *}$ & 0.9426 & 1.6026 \\
\hline Number of risk management strategies $=4$ & -- & -- & -- & $5.1666^{* *}$ & 1.0793 & 1.8406 \\
\hline Number of risk management strategies $=5$ & -- & -- & -- & $7.0441^{\text {**** }}$ & 1.8518 & 2.6478 \\
\hline Residual & $-1.1123^{* *}$ & -0.3584 & -0.3823 & $-1.1355^{* *}$ & -0.3456 & -0.3920 \\
\hline McFadden pseudo- $\mathrm{R}^{2}$ & & 0.191 & & & 0.199 & \\
\hline
\end{tabular}

${ }^{1}$ The baseline economic performance category is 'Low-income, low-wealth'. Note: Statistical significance of estimated parameters are based on Jackknife standard errors with ${ }^{*} p<0.10,{ }^{* *} p<0.05$, and ${ }^{* * * *} p<0.01$.

The most striking result is the finding of a strong impact of the number of adopted risk management strategies, based on the size and the significance of the estimated coefficients in both of the MNP regression models based on (7) and (8), on the likelihood of a farm operator being in the 'low-income, high-wealth' category of economic performance. Based on the model in (7), an increase in the number of adopted risk management strategies is found to increase, albeit in a linear fashion across all of the strategies, the likelihood of being in the 'low-income, high-wealth' category. Similarly, when the relationship between the number of risk strategies and economic performance is asserted based on equation (8) which allows for the impact of these strategies to vary across their multiple levels, the impact based on the value of the corresponding estimated coefficients on the probability of the farm household being in the 'low-income, high-wealth' category is shown to increase with the number of strategies adopted. Figure 3 illustrates this finding along with the observation, as reported in Table 4, that such an increase in the use of risk management strategies seems to have no discernable impact on the likelihood that a farm household would fall in the economic performance categories of 
'high-income, low-wealth' and of 'high-income, high-wealth'. ${ }^{19}$ The Figure also shows a decrease in the probability of a farm household being in a 'low-income, low-wealth' category from a level of 50\% when no risk management is used to a very low probability level when the household layers up in the usage of these strategies; particularly when all of the available strategies are used concurrently where such a likelihood approaches nearly zero percent.

Regardless to whether equation (7) or (8) is used in the MNP model of economic performance, statistically significant estimated coefficients in Table 4 show that farm households with farmers aged 55 or older, relative to their younger counterparts, have a higher likelihood of being in the 'low-income, high-wealth' category. Similar results are found when the operator has a college degree or beyond, or when the farm is organized as a family corporation, and when the farmland is fully owned by the farm household.

Results in Table 4 based on the models as described in (7) and (8) indicate that the likelihood of a farm household being in the 'high-income and low-wealth' category is higher if the farm operator has at least a college education, and if the farmer is married. Farmers working on the farm as hired managers and those who operate larger sized farms are more likely to be in this 'income-wealth' group than in the group of 'low income, low-wealth'.

Findings also indicate that, based on equations (7) and (8) and on the statically significant estimated coefficients, the likelihood of a farmer being in the 'high-income, high-wealth' category tends to increase with age of the operator, particularly if the age is 35 years or older (Table 4). Results also show that the probability of a farm household falling in the top economic performance is higher when the farm operator has at a college degree or a graduate education. Similarly, a farm household with a married farm operator or whose operator farms in the capacity of a hired manger and/or farms on a larger-sized farm is found with a higher likelihood of being among the top-performing group of farm households.
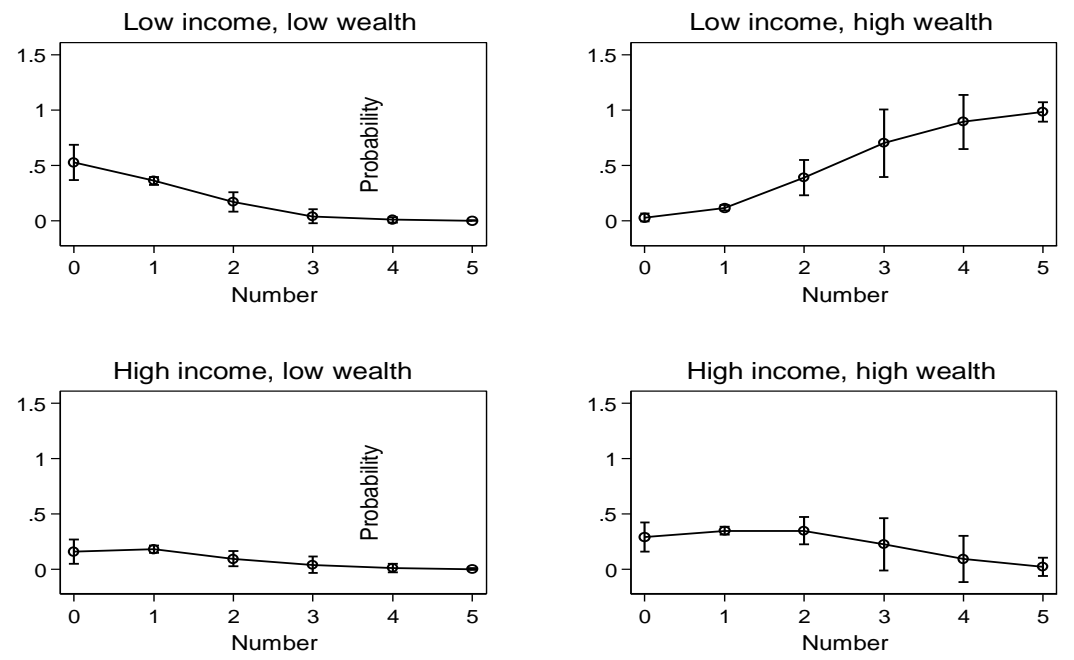

Figure 3. Predicted probabilities of economic performance by number of risk management strategies, 2015

Note: Confidence intervals are based on the Delta-method (see Oehlert 1992).

Source: estimated by the author using 2015 ARMS.

\section{Summary and Conclusions}

Many studies have extensively examined risk in production agriculture. Assessing the relationship between risk management and economic performance adds yet another vantage point to the continually growing body of risk-related literature. Data from the 2015 ARMS and multinomial probit regression models were used in an attempt to discern the impact of an increase in the number of risk management strategies on the likelihood of achieving a favorable economic performance by farm households. The contribution of this paper to research in this area is its use of a unique micro-level dataset with information, among others, on the farm production practices and the financial characteristics of farm operator households in the US. This information, in turn, allowed for the creation of a count index of risk management strategies, this in addition to a four-pronged economic categorization that has not previously been used in the literature.

Findings indicate that those farmers who are generally older, with at least a college education are more likely to be

${ }^{19}$ When Figure 3 is viewed with the information in Table 2, 'professional advice' appears as the most likely risk-management strategy to be adopted by farmers; this is regardless of the overall number of strategies utilized. 
among those farm households who are in the top income-wealth category of economic performance. These findings are not surprising as earlier studies have found, among other conclusions, a positive association between higher propensities of favorable economic outcome and older age, higher levels of education (e.g., Huffman and Lange 1989; Hoppe et al. 2005), and larger farm sizes (Perrin and Winkleman 1976; White and Hoppe 2012). Findings also indicate that older farmers, those with a college degree or beyond, and those who are inclined to layer up in the number of adopted risk management strategies are more likely to be in a performance category that favors wealth over income; i.e., in the category of 'low-income, high-wealth'.

The increased interest in issues related to risk abatement has been the subject of debate by policymakers not only in the U.S. where such a debate contributed to the shaping of some recent farm programs and regulation (e.g., as was introduced in the 2014 farm bill), but also in Europe as well. ${ }^{20}$ For example, a study by Sulewski and Kloczko-Gajewska (2014) assert that income management issues were added in the new law regulations concerning the Common Agricultural Policy after 2013. To the extent that farming is a business faced with ever-rising risks and uncertainty due to the vagaries of the weather, to crop and/or livestock diseases, and to unexpected fluctuating market conditions, how farmers manage risk becomes vital to their economic bottom line.

Findings from this paper that indicate a higher likelihood of wealth-biased economic wellbeing to be associated with increased usage of risk management strategies should help in shedding light on what farmers could do, not only to address how to avoid the potential of negative outcomes from price or market and production factors that sometime fall beyond their control, but also to increase their likelihood in moving to a favorable economic position. As noted by Turvey (1992), an unintended effect of using one of the risk management strategies as referenced in this paper, namely crop insurance, is the potential for increased likelihood of high-risk crops entering farmers' production plans, with such likelihood increasing with increased coverage coupled with higher levels of insurance subsidies.

One limitation of this research is that it only considered a partial listing of risk management strategies; primarily due to lack of needed data. For example, the 2015 ARMS did not have information on farmers' use of futures and options markets to lock in prices when crops are harvested. Other strategies with available information in the ARMS that will be explored in future research considering their potential role in lessening the variability in total income will include those related to off-farm labor participation and to participation in farm programs; despite the complexities surrounding their use due to endogeneity concerns and the need for finding appropriate instruments.

\section{Acknowledgements}

The author is grateful to Ryan Williams (Economic Research Service) for providing the climate data needed in this research.

\section{References}

Ahrendsen, B. L., \& Katchova, A. L. (2012). Financial ratio analysis using ARMS data. Agricultural Economics Staff Paper \# 477, University of Kentucky. https://doi.org/10.1108/00021461211250492

Antle, J. M. (1983). Incorporating risk in production analysis. American Journal of Agricultural Economics, 65(5), 1099-1106. https://doi.org/10.2307/1240428

Artolini, F., Andreoli, M., \& Brunori, G. (2014). Explaining determinants of the on-farm diversification: empirical evidence from Tuscany region. Bio-based and Applied Economics, 3(2), 137-157.

Atwood, J., Shaik, S., \& Watts, M. (2003). Are crop yields normally distributed? A reexamination. American Journal of Agricultural Economics, 85(4), 888-901. https://doi.org/10.1111/1467-8276.00495

Ball, V. E., Butault, J. P, \& Nehring, R. (2002). U.S. agriculture, 1960-96: a multilateral comparison of total factor productivity. In V.E. Ball, \& G.W. Norton (Eds.) Agricultural productivity: Measurement and source of growth, p.11. Kluwer Academic Publishers, Norwell, Massachusetts, USA. https://doi.org/10.1007/978-1-4615-0851-9_2

Barry, P. J. (ed.). (1984). Risk management in agriculture. Iowa State University Press, Ames.

Barry, P. J., \& Stanton, B. F. (2003). Major ideas in the history of agricultural finance and farm Management. WP 2003-02. Cornell University, Ithaca, New York.

Barry, P. J., Escalante, C. L., \& Bard, S. K. (2000). Economic risk and the structural characteristics of farm businesses. American Agricultural Economics Association Annual Meeting, July 30-August 2, Tampa, Florida.

Blundell, R., Griffith, R., \& Van Reenen, J. (1995). Dynamic count data models of technological innovation. The Economic Journal, 105(429), 333-344. https://doi.org/10.2307/2235494

\footnotetext{
${ }^{20}$ For more information with regard to the 2014 farm bill, see Risk Management Agency at:

https://www.rma.usda.gov/news/currentissues/farmbill/
} 
Brown, J. P., \& Weber, J. G. (2013). The off-farm occupations of U.S. farm operators and their spouses. EIB 117. U.S. Department of Agriculture, Washington, DC.

Bunch, D. S. (1991). Estimability in the multinomial probit model. Transportation Research, Part B: Methodological, 25(1), 1-12. https://doi.org/10.1016/0191-2615(91)90009-8

Cai, J., Guanming, S., \& Hu, R. (2016). An impact analysis of farmer field school in China. Sustainability, 8(137), 1-14. https://doi.org/10.3390/su8020137

Chavas, J. P., \& Shi, G. (2015). An economic analysis of risk, management, and agricultural technology. Journal of Agricultural and Resource Economics, 40(1), 63-79.

Cooper, J. C. (2003). A joint framework for analysis of agri-environmental payment programs. American Journal of Agricultural Economics, 85(4), 976-987. https://doi.org/10.1111/1467-8276.00501

D’ Antoni, J., Mishra, A., \& Chintawar, S. (2009). Predicting financial stress in young and beginning farmers in the United States. Paper presented at the Southern Agricultural Economics Association annual meeting, Atlanta, Georgia, January 31- February 3.

Daganzo, C. (1979). The multinomial probit: The theory and its application to demand forecasting, New York, Academic Press.

Dismukes, R., \& Durst, R. (2006). Whole-Farm Approach to a Safety Net. EIB 15. U.S. Department of Agriculture, Washington, DC.

Dubman, R. W. (2000). Variance Estimation with USDA's Farm Costs and Returns Surveys and Agricultural Resource Management Study Surveys. ERS Staff Paper, AGES 00-01. U.S. Department of Agriculture, Washington, DC.

El-Osta, H. (2007). The determinants of a quality of life indicator for farm operator households: Application of zero-inflated count-data models. Journal of Applied Research in Quality of Life, 2(3), 145-163. https://doi.org/10.1007/s11482-007-9035-1

El-Osta, H. (2014). An index of socio-economic well-being of U.S. farm households. Modern Economy, 5(12), 1120-1131. https://doi.org/10.4236/me.2014.512104

El-Osta, H., Mishra, A., \& Morehart, M. (2007). Determinants of economic well-being among farm operator households. Agricultural Economics, 36(3), 291-304. https://doi.org/10.1111/j.1574-0862.2007.00207.x

Fruend, R. J. (1956). The introduction of risk into a programming model. Econometrica, 24(3), 253-263. https://doi.org/10.2307/1911630

Fuller, A. M., \& Mage, J. A. (1976). Part-time farming: Problem or resource in development. Norwich, England: GeoAbstract Limited, for University of Guelph, Canada.

Gebremedhin, T. G., \& Christy, R. D. (1996). Structural changes in U.S. agriculture: Implications for small farms. Journal of Agricultural and Applied Economics, 28(1), 57-66. https://doi.org/10.1017/S1074070800009457

Greene, W. H. (2008). Econometric Analysis. Sixth edition. Upper Saddle River, NJ: Prentice-Hall.

Hardaker, J. B., Huirne, R. B. M., \& Anderson, J. R. (1997). Coping with risk in agriculture. New York, CAB International.

Harwood, J., Heifner, R., Coble, K., Perry, P., \& Somwaru, R. (1999). Managing risk in farming: Concepts, research and analysis, AER-774. U.S. Department of Agriculture, Washington, DC.

Hazell, P. B. R. (1971). A linear alternative to quadratic and semivariance programming for farm planning under uncertainty. American Journal of Agricultural Economics, 53(1), 53-62. https://doi.org/10.2307/3180297

Heady, E. O. (1952). Economics of agricultural production and resource use, Prentice Hall, Englewood Cliffs,

Heady, E. O., \& Sonka, S. T. (1974). Farm size, rural community income, and consumers' welfare. American Journal of Agricultural Economics, 56(3), 534-542. https://doi.org/10.2307/1238605

Hoppe, R. A., Korb, P., Green, R., Mishra, A., \& Sandretto, C. (2005). Characteristics of top-performing farms. In D. E., Banker, \& MacDonald, J. M. (Eds.). Structural and financial characteristics of U.S. farms-2004 family farm report. AIB-797. U.S. Department of Agriculture, Washington, DC.

Huffman, W. E., \& Lange, M. D. (1989). Off-farm work decisions of husbands and wives: Joint decision making. Review of Economics and Statistics, 71(3), 471-480. https://doi.org/10.2307/1926904

Hungerford, A., \& O'Donoghue, E. (2016). Federal crop insurance options for upland cotton farmers and their revenue effects, ERR-218, U.S. Department of Agriculture, Washington, DC. 
https://www.ers.usda.gov/webdocs/publications/80670/err-218.pdf?v=42669

Hungerford, A., Motamed, M., \& Cessna, J. (2017). Managing agricultural risk under different scenarios: Selected 2014 Farm Act programs. Amber Waves, February.

https://www.ers.usda.gov/amber-waves/2017/januaryfebruary/managing-agricultural-risk-under-different-scenarios -selected-2014-farm-act-programs/

Johnson, D. G. (1947). Forward prices for agriculture, University of Chicago Press, Chicago.

Just, R. E., \& Pope, R. D. (1979). Production function estimation and related risk considerations. American Journal of Agricultural Economics, 61(2), 277-284. https://doi.org/10.2307/1239732

Key, N., Prager, D., \& Burns, C. (2017). Farm household income volatility: An analysis using panel data from a national survey, ERR-226, U.S. Department of Agriculture, Washington, DC.

Kuethe, T. H., \& Morehart, M. (2012). The profit impacts of risk management tool adoption. Agricultural Finance Review, 72(1), 104-116. https://doi.org/10.1108/00021461211222178

Lambert, D. (1992). Zero-inflated poisson regression, with an application to defects in manufacturing. Technometrics, 34(1), 1-14. https://doi.org/10.2307/1269547

Lochner, L., \& Moretti, E. (2015). Estimating and testing models with many treatment levels and limited instruments. Review of Economics and Statistics, 97(2), 387-397. https://doi.org/10.1162/REST_a_00475

Long, J. S. (1997). Regression models for categorical and limited dependent variables. Tousand Oaks, CA: Sage Publications, Inc.

Mapp, H. P., Hardin, M. L., Walker, O. L., \& Persaud, T. (1979). Analysis of risk management strategies for agricultural producers. American Journal of Agricultural Economics, 61(5), 1071-1077. https://doi.org/10.2307/3180377

Meuwissen, M., Asseldonk, M., \& Huirne, R. (eds.). (2008). Income stabilization in European agriculture: Design and economic impact of risk management tools. Wageningen Academic Publisher. https://doi.org/10.3920/978-90-8686-650-2

Miranda, M. J., \& Glauber, J. W. (1997). Systemic risk, reinsurance, and the failure of crop insurance markets. American Journal of Agricultural Economics, 79(1), 206-215. https://doi.org/10.2307/1243954

Mishra, A. K., \& Morehart, M. J. (2001). Factors affecting returns to labor and management on U.S. dairy farms. Agricultural Finance Review, 61(2), 123-140. https://doi.org/10.1108/00214790180001120

Mishra, A. K., \& Sandretto, C. L. (2002). Stability of farm income and the role of nonfarm income in U.S. Agriculture. Review of Agricultural Economics, 24(1), 208-221. https://doi.org/10.1111/1058-7195.00014

Mishra, A. K., El-Osta, H. S., \& Johnson, J. (1999). Factors contributing to earnings success of cash grain farms. Journal of Agriculture and Applied Economics, 31(3), 623-637. https://doi.org/10.1017/S1074070800008889

Mishra, A. K., El-Osta, H. S., Morehart, M. J., Johnson, J. D., \& Hopkins, J. W. (2002). Income, wealth, and the economic well-being of farm households. AER-812. U.S. Department of Agriculture, Washington, DC.

O'Donoghue, E., Hoppe, R., Banker, D., Ebel, R., Fuglie, K., Korb, P., ... Sandretto, C. (2011). The changing organization of U.S. farming. EIB-88. U.S. Department of Agriculture, Washington, DC.

Oehlert, G. W. (1992). A note on the delta method. American Statistician, 46(1), 27-29.

Ollinger, M., MacDonald, J., \& Madison, M. (2005). Technological change and scale economies in the poultry industry. American Journal of Agricultural Economics, 87(1), 116-129. https://doi.org/10.1111/j.0002-9092.2005.00706.x

Park, T., Ahearn, M., Covey, T., Erickson, K., Harris, J. M., Ifft, J., ... Williams, R. (2011). Agricultural Income and Finance Outlook. AIS-91. U.S. Department of Agriculture, Washington, DC.

Perrin, R., \& Winkleman, D. (1976). Impediments to technical progress on small versus large farms. American Journal of Agricultural Economics, 58(5), 888-894. https://doi.org/10.2307/1239988

Robison, L. J., \& Barry, P. J. (1987). The competitive firm's response to risk. New York: Macmillan (pp. 17-22).

Sorensen, J. B. (1999). Zero-inflated and negative binomial regression models. Stata Technical Bulletin Reprints, 194-199.

StataCorp. (2015). Stata Statistical Software: Release 14. College Station, TX: StataCorp LP.

Sulewski, P., \& Kloczko, G. A. (2014). Farmers' risk perception, risk aversion and strategies to cope with production risk: an empirical study from Poland. Studies in Agricultural Economics, 116(3), 140-147. https://doi.org/10.7896/j.1414 
Tack, J., Harri, A., \& Coble, K. (2012). More than mean effects: Modeling the effect of climate on the higher order moments of crop yields. American Journal of Agricultural Economics, 94(5), 1037-1054. https://doi.org/10.1093/ajae/aas071

Terza, J. V., Basu, A., \& Rathouz, P. J. (2008). Two-stage residual inclusion estimation: Addressing endogeneity in health econometric modeling. Journal of Health Economics, 27(3), 531-543. https://doi.org/10.1016/j.jhealeco.2007.09.009

Theil, H. (1971). Principles of econometrics. New York: John Wiley and Sons.

Train, K. E. (2003). Discrete choice methods with simulation. New York: Cambridge University Press. https://doi.org/10.1017/CBO9780511753930

Turvey, C. G. (1992). An economic analysis of alternative farm revenue insurance policies. Canadian Journal of Agricultural Economics, 40(3), 403-426. https://doi.org/10.1111/j.1744-7976.1992.tb03704.x

Ullah, R., Shivakoti, G. P., Zulfiqar, F., \& Kamran, M. A. (2016). Farm risks and uncertainties: Sources, impacts and management. Outlook on Agriculture 45(3), 199-205. https://doi.org/10.1177/0030727016665440

Vuong, Q. H. (1989). Likelihood ratio tests for model selection and non-nested hypotheses. Econometrica, 57(2), 307-333. https://doi.org/10.2307/1912557

White, T. K., \& Hoppe, R. A. (2012). Changing farm structure and the distribution of farm payments and Federal crop insurance. EIB-91. U.S. Department of Agriculture, Washington, DC.

\section{Copyrights}

Copyright for this article is retained by the author(s), with first publication rights granted to the journal.

This is an open-access article distributed under the terms and conditions of the Creative Commons Attribution license which permits unrestricted use, distribution, and reproduction in any medium, provided the original work is properly cited. 